\title{
Environmental Regulations and the Location Choice of FDI in Pollution Intensive Industries: Evidence from China
}

\author{
W.H. LI ${ }^{1}$, J.Q. LIU ${ }^{1}$ \& D.S. DING ${ }^{1}$, H.L. HE ${ }^{2}$ \\ ${ }^{1}$ School of Economics \& Management, Harbin Engineering University, Heilongjiang, China \\ ${ }^{2}$ College of Civil and Architectural Engineering, Heilongjiang Institute of Technology, Heilongjiang, \\ China
}

KEYWORD: Environmental regulations, LOCFDI; Pollution intensive industries

ABSTRACT: As more foreign direct investment (FDI) inflows to pollution intensive industries in China, policy makers become concerned with the environmental problems causing by FDI. Because of environmental regulation in different regions can be formulated with different strength, whether or not environmental regulations in different regions can affect the location choice of FDI in China. Using the data of pollution intensive industries in 28 provinces, we examine the environmental regulation effects on the location choice of FDI (LOCFDI). Besides the regional total product volume and the area economic development level, the results also show that environmental regulation is one of the important determinants of LOCFDI. In some developed provinces, stricter environmental regulations have no effective influence on LOCFDI. While in other developing provinces, the environmental regulations have particularly significant effects on $L O C F D I$.

\section{INTRODUCTION}

Foreign direct investment (FDI) has been among the fastest growing economic activities around the world, especially in China. While this growth has increased the large scaled capital, advanced technologies, and export trades, it has been accompanied by serious environmental problems as the foreign funds transfer to be invested in pollution intensive industries in China. Especially many polluting industries are located in the densely populated metropolitan areas where emissions exposure causes serious damage to human health and economic activity.

Beginning in the mid 1960's, the thought of using environmental regulation policies to control pollution levels started to emerge in China, such as improving the access threshold to pollution intensive industries, closing the small enterprises with high energy dissipation and heavy pollution, and decreasing the pollutant sources connected to the eco-environment system. Furthermore, according to the environment protection law of the People's Republic of China (one of environmental regulation policies in China), the regional authority has right to formulate the index of local contamination and collect the emission fees on the basis of the local situations, and the regional standards cannot lower than national standards. Therefore, we analyze the relationship between the different regional environmental regulation and location choice of FDI in pollution intensive industries using industrial level data over 8 years in 28 provinces in China. The results will help the regional authorities to balance attracting foreign investment and protecting the environment.

\section{Literature Review}

There are different viewpoints on the issue of how environmental regulations affect FDI. Several theoretical papers have examined the linkages between environmental regulation and competitions, and concluded that strict environmental regulation may attract FDI. Cole and Elliott (2005) found that domestic sectoral capital intensity and pollution abatement costs have had a positive and significant effect on US FDI to Brazil and Mexico. Lu Xin-de, Liu Xiao-ming and Liu Chang-mei (2010) present a statistical test of the impact of environmental regulations on the capital movement of foreign investment, and indicated strict environmental regulation can act as an incentive for FDI Bouwe R. Dijkstra, Anuj J. Mathew and Arijit Mukherjee(2011) show that a foreign firm may invest in the home country although total costs (taking the costs of production, environmental taxation and transportation into account) are higher there. 
An alternative view is that environmental regulations have no effect on plant location. The basic argument is either that cost effects are so small as to be negligible or that increased environmental quality is reflected in reduced employee compensation. Eskeland and Harrison (2003) examined the pattern of foreign investment across industries within Mexico, Venezuela, Morocco, and Cote d'Ivoire. They found that abatement costs are not significant determinants of the distribution of foreign investment among manufacturing industries within a country.

The above previous studies assume that there is some or no relationship between FDI and environment regulation. However, FDI-environment regulation relationship is controversial, especially when FDI flows to pollution intensive industries in different regional area. Another shortcoming of previous empirical studies lies in measuring the strictness of environmental regulations on FDI from the whole area. Therefore, on the basis of the previous studies, the paper uses a theoretical modeling to explore the problem: the regional differences of the environmental regulation's effects on FDI in pollution intensive industries in China.

\section{Empirical Model and Data}

\section{The Theoretical Model}

We hypothesize that the environmental regulation will affect the inflow of FDI to China. Usually FDI in the pollution intensive industries will choose a low environmental restriction as the investment location. On the basis of this hypothesis, we examine the effect of the environmental regulation on the location of FDI in pollution intensive industries using a panel model. Then we estimate the following reduced form equation:

$$
\operatorname{LOCFDI}_{i t}=\beta_{0}+\beta_{1} R E G U_{i t}+\beta_{2} D Q Z_{i t}+\beta_{3} A G D P_{i t}+\varepsilon_{i t}
$$

Where $i$ indexes provinces, $t$ indexes time, $\beta 0$ is the intercept term and $\beta 1, \beta 2 、 \beta 3$ respectively denotes regression coefficient of environmental regulation, regional total product volume and area economic development level, $\varepsilon$ is the stochastic deviation.

\section{The meaning of each variable}

The explained variable - LOCFDI.As indicated by Guo Jian and Wang Tao-feng (2009), the number of FDI in pollution intensive industries not only shows the area that the foreign investors prefer to move but also shows the situation that how much the foreign investors will invest. Thus, the $L O C F$ $D I$ is measured by the ratio of pollution intensive's foreign investments in different regions to the whole national FDI.

The explanatory variable -REGU.On the basis of Li Wan-hong and other scholars' method of testing the environmental regulation, the $R E G U$ is using the ratio of the contamination emission of the pollution intensive industries in different regions to the total product volume in the whole industries. Because the value presents the relationships between the total product volume and the contamination emission, the ratio can eliminate the effect of industry scale on environmental regulation intensity. When the value is lower, the intensity of the environmental regulation will be higher. What's more the amount of the contamination emission can reflects the basic situations of the environmental regulation [8].

The controlled variable $D Q Z$ and $A G D P$. The variable, regional industrial total product $(D Q Z)$ shows the industrial development degree of the specific area. The high product volume in the area means the high industrial development degree.

The area economic development level $(A G D P)$ reflects the competitive ability in a specific area, which is an important factor for the foreigners to make a decision on invest. Considering the distraction of the populations and the size in different areas, we use the per capita GDP to interpret the economic development degree in different regions.

\section{Industry Selection and Data source}

On the basis of the Xia You-fu and Jiang Ke's researches, the pollution intensive industries in our paper refer to 19 industries in China, including coal mining and washing industry, petroleum and natural gas industry, mining and processing of ferrous metals ores, mining and processing of non - ferrous metal ores, mining and processing of nonmetal ores, nonmetallic minerals industry, papermaking and paper products, manufacturing of raw chemical materials and chemical products, electricity-heat production and supply industry, agricultural and sideline products processing industry, medical and 
pharmaceutical products, chemical fiber, smelting and pressing of ferrous metals, smelting and pressing of nonferrous metals, metal products, petroleum-coking and nuclear fuel processing, rubber and plastic products industry, fur industries, and textile industry.

As some data is missing in Hainan, Yunnan, Tibet Macao, Hongkong, Taiwan, the paper uses 28 provinces panel data in 2005-2012 and 261 observations to research the relationship between the different regional environmental regulation and location choice of FDI in pollution intensive industries. The data were got from China Economy Network's database, Chinese environment statistical yearbook and Chinese statistical yearbook.

\section{Estimations and Results}

\section{Root of unity test}

In order to avoid spurious regression and grantee the data's stability, the first step is to test the unit root. We show the test results using LLC, ADF Fisher and PP Fisher in Table 1. As each Prob. is lower than $5 \%$, we reject the null hypothesis of unit root.

Table 1 Results of the root of unity test

\begin{tabular}{llcc}
\hline Variables & Methods & Statistic & Prob. \\
\hline \multirow{2}{*}{ LOCFDI } & LLC * & -2.15075 & 0.0157 \\
& ADF-Fisher & 65.9273 & 0.0171 \\
\multirow{2}{*}{$R E G U$} & PP - Fisher & 111.152 & 0.0000 \\
& L LC* & -25.9752 & 0.0000 \\
& ADF-Fisher & 254.030 & 0.0000 \\
$D Q Z$ & PP - Fisher & 255.671 & 0.0000 \\
& LLC* & -12.4608 & 0.0000 \\
\multirow{3}{*}{$A G D P$} & ADF-Fisher & 183.311 & 0.0000 \\
& PP - Fisher & 186.713 & 0.0000 \\
& LLC* & -12.6770 & 0.0000 \\
& ADF-Fisher & 186.150 & 0.0000 \\
& PP - Fisher & 190.738 & 0.0000 \\
\hline
\end{tabular}

\section{Co-integration test}

We also performed co-integration test in order to guarantee the stability of the data after unit root test. The meaning of the co-integration test is to judge whether the two variables will keep a longlasted equilibrium relationship. When two group variables both are same the order in one-stage, the co-integration test can be continued. The results of co-integration test are shown in Table 2.

Table 2 Results of co-integration test

\begin{tabular}{lllc}
\hline & \multicolumn{1}{c}{ Variables } & T statistic & Prob. \\
\hline$L O C F D I$ & $R E G U$ & -3.006341 & 0.0013 \\
$D Q Z$ & $A G D P$ & & \\
\hline
\end{tabular}

As is showed in Tab. 2, the $\mathrm{P}$ is 0.0013 , lower than $1 \%$ tested by ADF, which means the variables keep a long- lasted relation and variables also keep co-integration relation.

\section{Hausman Test}

Hausman test is the method to judge whether the model is a fixed effect model or a random effect model. As the results showed in Table 3, the value of the statistic is 73.1700, and the value of Prob. is 0.0000 . Then we can choose the fixed effect models to research.

Table 3 Results of Hausman test

\begin{tabular}{lrlll}
\hline \multicolumn{2}{c}{ Variables } & Statistic & Prob. & $\begin{array}{l}\text { Model } \\
\text { assumptions }\end{array}$ \\
\hline $\begin{array}{l}\text { LOCFDI } \\
D Q Z\end{array}$ & REGU & 73.1700 & 0.0000 & Fixed effects model \\
\hline
\end{tabular}




\section{F Test}

After we choose the fixed effect models to research, we also should use the F test to decide whether the models are varying coefficient models, variable intercept models or the mixing coefficient models. The results of $F$ test are shown in Table 4 .

Table $4 \mathrm{~F}$ test of panel data

\begin{tabular}{cc}
\hline Variables & Values \\
\hline $\mathrm{S}_{1}$ & 5.540974 \\
$\mathrm{~S}_{2}$ & 14.88161 \\
$\mathrm{~S}_{3}$ & 20.94738 \\
\hline
\end{tabular}

According to the equations as follows,

$$
\begin{aligned}
& F_{1}=\frac{\left(S_{2}-S_{1}\right) /[(N-1) K]}{S_{1} /[N T-N(K+1)]} \quad F[(N-1) K, N(T-K-1)] \\
& F_{2}=\frac{\left(S_{3}-S_{1}\right) /[(N-1)(K+1)]}{S_{1} /[N T-N(K+1)]} F[(N-1)(K+1), N(T-K-1)]
\end{aligned}
$$

We can get $F_{1}=2.33, F_{2}=2.88$. Because $F_{1}, F_{2}$ are both bigger than the critical value under the significance level, so we choose the varying coefficient models in our research.

\section{Regression analysis}

With software Eviews6.0, we use the weighted least square to estimate the fixed effect model. The results are showed in Table 5.

Tab. 5 Regression results of panel data

\begin{tabular}{lrrr}
\hline \multicolumn{1}{c}{ Variables } & Coefficient & T statistic & Prob. \\
\hline$D Q Z$ & 1.4205 & 4.792269 & 0.000 \\
$A G D P$ & 0.0589 & 4.172218 & 0.000 \\
Beijing & 151.70 & 1.886316 & 0.060 \\
Tianjin & 271.76 & 3.038612 & 0.002 \\
Hebei & 212.35 & 5.890355 & 0.000 \\
Shaanxi & 494.46 & 10.24178 & 0.000 \\
Neimenggu & 352.00 & 8.379014 & 0.000 \\
Liaoning & 295.63 & 8.640195 & 0.000 \\
Jilin & 430.81 & 18.08807 & 0.000 \\
Heilongjiang & 283.99 & 9.436627 & 0.000 \\
Shanghai & 126.08 & 1.957298 & 0.051 \\
Jiangsu & 37.400 & 0.808729 & 0.419 \\
Zhejiang & 113.71 & 3.518749 & 0.000 \\
Anhui & 206.04 & 9.683915 & 0.000 \\
Fujian & 114.92 & 9.841742 & 0.000 \\
Jiangxi & 195.90 & 10.29997 & 0.000 \\
Shandong & 128.28 & 1.292343 & 0.197 \\
Henan & 220.71 & 5.983867 & 0.000 \\
Hubei & 152.31 & 8.460770 & 0.000 \\
Hunan & 129.73 & 8.527619 & 0.000 \\
Guangdong & 42.138 & 0.946311 & 0.345 \\
Guangxi & 59.366 & 10.71235 & 0.000 \\
Chongqing & 68.703 & 10.23574 & 0.000 \\
Sichuan & 144.20 & 8.210143 & 0.000 \\
Guizhou & 439.75 & 12.28623 & 0.000 \\
Shanxi & 275.76 & 10.99370 & 0.000 \\
Gansu & 416.86 & 11.71305 & 0.000 \\
Qinghai & 355.30 & 11.09422 & 0.000 \\
Ningxia & 114.32 & 7.538714 & 0.000 \\
Xinjiang & 423.60 & 10.51614 & 0.000 \\
\hline Adjusted R & & 0.756723 & \\
$\quad F$ & & 24.12174 & \\
\multicolumn{1}{c}{ D.W. } & & 1.560344 & \\
\hline & & & \\
\hline & & & \\
\hline
\end{tabular}


Firstly, the coefficients of the environmental regulation in Jiangsu,Shandong, Guangdong,Beijing,Shanghai are not significant test at 5\% level.So the environmental regulation in these provinces shows non-significant influence on the FDI in pollution intensive industries. The reasons maybe the environmental regulation is not the only element of pollution intensive industries FDI location choosing. The regional total production and the regional economic development degree also have the impact on the location choosing. What's more, the regional total production is more important than the economic development degree for location choice of FDI in pollution intensive industries.

Secondly, except these five provinces mentioned above, each coefficient of the environmental regulation is positive and passes the significance test, and the total regression result is fit enough. That is, when environmental regulation becomes harsher, the effect on FDI in pollution intensive industries to choose a proper location is greater as well. It is worth mentioning that the coefficients in Shanxi, Jilin, Guizhou, Gansu and Xinjiang are relatively larger more than 400, which means the increase of one intensity unity of the environmental regulation, the FDI to these provinces will much bigger than other provinces.

\section{Conclusions}

According to the results, the environmental regulation is one of the important determinants of the LOCFDI. In some developed provinces, stricter environmental regulations have no effective influence on the $L O C F D I$. While in other developing provinces, the environmental regulations have particularly significant effects on $L O C F D I$. The results also show that the regional total product volume and the area economic development level also have the significant influence on the choosing a proper location for the pollution intensive industries FDI.

\section{Acknowledgements}

This paper is funded by the National Science Foundation of China for Youth ((NO.71202037), Natural Science Foundation of Heilongjiang Province (NO.G201210), Philosophy and Social Science Project of Heilongjiang Province (NO.11E111), Fundamental Research Funds for the Central Universities (NO.HEUCF140901). The views expressed are authors' alone.

\section{References}

[1] Wang Jun-feng, Yan Yong \& Yang Chun-yu(2012), Research on Regional Difference's Impact on Pollution Charge and Tax in China and the Countermeasures, China Population Resources and Environment, vol.22,no.3,pp.94-97.

[2] Zhao Wen-hui,Gao Yan \& Dai Tian-sheng(2010),Model for regulation and control with emission tax of trans-boundary pollution, Systems Engineering-Theory \& Practice, vol.30, no.2, pp. 221226.

[3] Cole, M.A. \& Elliott, R.J.R. (2005), FDI and the Capital Intensity of 'Dirty' Sectors: A Missing Piece of the Pollution Haven Puzzle, Review of Development Economics, Vol. 9, 4, pp. 530548.

[4] Lu Xin-de,Liu Xiao-ming \& Liu Chang-mei(2010),A Positive Analysis of the Influences of China's Environmental Regulation on Foreign Direct Investment. Shandong Economy, vol.26, no.1, pp. 86-116.

[5] Bouwe R.Dijkstra, Anuj J.Mathew \& Arijit Mukherjee(2006), Evironment regulation: An incentive for foreign direct investment, NBER Working Paper 3942.

[6] Gunnar.S. Eskeland \& Ann.E.Harrison (2003),Moving to greener pastures' Multinationals and the Pollution haven hypothesis.Journal of Development Economics, vol.70, pp. 1-23.

[7] Francesco Testa a,c, Fabio Iraldo a,b \& Marco Frey (2011), The effect of environmental regulation on firms' competitive performance: The case of the building \& construction sector in some EU regions, Journal of Environmental Management, vol.92, no.9, pp. 2136-2144. 
[8] Guo Jian \& WangTao-feng(2009),Agglomeration Effects, Environmental Regulation Policy and Foreign Direct Investment Location Choice-According to the New Economic Geography, Industrial Economics Research, no. 4, pp. 29-37.

[9] Sunghoon Chung (2014),Environmental regulation and foreign direct investment: Evidence from South Korea, Journal of Development Economics, vol.108, pp. 222-236.

[10] Ulrich J. Christopher D (2009), Agglomeration Effects in Foreign Direct Investment and the Pollution Haven Hypothesis, Environmental Resource Econ, vol. 43, pp. 231-256.

[11]Fu Jingyan,Li Lisha(2010),FDI, Environmental Regulation and Pollution Haven Effect-Empirical Analysis of China's Provincial Panel Data. Journal of Public Management, vol.7, no.3, pp. 65126.

[12]LI Wan-hong,BI Ke-xin \& SUN Bing(2013), Research on the Effect of Environmental Regulation Intensity on Green Technological Innovation of Pollution Intensive Industries-Empirical Test Based on Panel Data of 2003-2010”. Research \& Development Management, vol.25, no.6, pp. 72-81. 